\title{
Spatial memory and food searching mechanisms of cattle
}

\author{
EMILIO A. LACA
}

Author is assistant professor, Department of Agronomy and Range Science, University of Calif., Davis, Calif. 95616. At the time of the research the author was Assistant Professor, Department of Range, Wildlife and Fisheries Management, Texas Tech University, Lubbock, Tex.

Abstract

Uneven distribution of grazing negatively impacts rangelands through over- and under utilization of resources. The goal of this study was to quantify the role of experience on search pattern and foraging efficiency of cattle. Steers (Bos taurus $\times$ B. indicus) were exposed once daily during 15-20 min. sessions to 3 food-distribution treatments: VR (variable-random, food locations were changed randomly and daily), CR (constant-random, food locations were randomly set at the beginning and remained the same throughout the experiment), and $\mathrm{CC}$ (constant-clumped, food locations were constant and clumped in groups of 5). Pelleted feed was available in 20 out of 64 feeders arranged in 8 rows and 8 columns, with neighboring locations $5 \mathrm{~m}$ apart. Encounter rate of food locations was partitioned into search speed, total number of visits per unit distance walked, ratio of different (not previously visited within the session) locations to total visits (including revisits), and ratio of food locations to different locations visited. Intake rate increased $(P<0.01)$ as animals gained experience, but more slowly in variable-random than constant-clumped and constant-random. Residence time at food locations declined $(\mathbf{P}<$ 0.01) with increasing experience. Intake rate was negatively affected $(P<0.01)$ by search time per food location, which in turn was determined by the steers' ability to remember food locations. Steers in constant random and constant clumped used long-term spatial memory to return to food locations, and ignored areas where no food was found $(P<0.01$ ). Conversely, steers in variable random used a strategy based on avoidance of locations already visited within sessions. Thus, in constant random and constant clumped food search was more efficient $(P<$ 0.01) and concentrated in certain areas, whereas in variable random it was less efficient and more evenly distributed over the whole area. The results of this study suggest that impeding spatial memory could improve grazing patterns.

Key Words: foraging behavior; grazing distribution; searching behavior; spatial learning.

Many of the negative impacts of cattle (Bos taurus) grazing in rangelands are caused by poor spatial distribution of grazing pressure (Holechek et al. 1995). These effects occur even if stocking

\footnotetext{
Research was funded by National Science Foundation Grant IBN-9311463 and by the Department of Range, Wildlife and Fisheries Management of Texas Tech University.

The author is grateful to Stan Bradbury, Gayle Heinrich, Carlos Villalobos and Kristin Whittenburg, who greatly contributed to this project. M. Wallis De Vries, D. Lott. J. Walker and 3 anonymous reviewers made helpful comments to improve the manuscript.

Manuscript accepted 2 Nov. 1997.
}

\section{Resumen}

Una distribución no uniforme del pastoreo afecta negativamente al pastizal a través de la sobre- y subutilización de los recursos. El objetivo de este estudio fue determinar el efecto de la experiencia sobre el patrón de búsqueda y eficiencia de forrajeo en vacunos. Novillos (Bos taurus $x$ B. indicus) fueron sometidos una vez por día, durante 15-20 minutos por sesión, a 3 tratamientos de distribución espacial de alimento: VR (variableal azar, posiciones con alimento cambiadas al azar diariamente), CR (constante-al azar, posiciones con alimento fueron determinadas al azar al comienzo del experimento y permanecieron constantes hasta el final), CC (constante-agrupado, posiciones constantes y en grupos de a 5). Alimento peleteado fue puesto en 20 de los 64 comederos dispuestos en 8 filas y 8 columnas con 5 m entre posiciones adyacentes. La tasa de encuentros de posiciones con alimento se desglosó en velocidad de búsqueda, número de posiciones visitadas por unidad de distancia caminada, número de posiciones distintas (excluyendo aquellas visitadas anteriormente dentro de la sesión) visitadas por visita (incluyendo posiciones ya visitadas), $y$ número de posiciones con alimento visitadas por cada posición distinta visitada. La tasa de consumo aumentó $(P<0.01)$ a medida que los animales adquirieron experiencia, pero el aumento fue mas lento en VR que en CC y CR. El tiempo de residencia por posición con alimento disminuyó (P < 0.01) a medida que aumentó la experiencia. La tasa de consumo fue afectada negativamente $(P<0.01)$ por el tiempo de búsqueda por posición con alimento, lo que a su vez fue determinado por la habilidad de los novillos de recordar las posiciones con alimento. Los novillos en CC y CR usaron memoria espacial a largo plazo para regresar a posiciones con alimento, e ignoraron áreas donde el alimento no se encontraba $(P<0.01)$. En cambio, los novillos en VR usaron una estrategia basada en evitar áreas recientemente visitadas en la misma sesión. Por lo tanto, en CR y CC la búsqueda de alimento fue mas eficiente ( $P$ < 0.01) y se concentró en ciertas áreas, mientras que en VR la búsqueda fue menos eficiente y más uniformemente distribuida sobre toda el área disponible. Los resultados de este estudio sugieren que los patrones espaciales de pastoreo se podrian mejorar mediante la obstrucción de la memoria espacial de vacunos.

rates are moderate. Bailey et al. (1989a) suggested that cattle develop short and long-term memory of foraging locations in a pasture. Short-term memory may be used to avoid recently depleted food locations. A series of studies (Bailey 1988; Bailey et al. 1989a; Bailey et al. 1989b) demonstrated that cattle have excellent short-term memory. Cattle were able to remember depleted locations for up to 8 hours (Bailey et al. 1989a). New management techniques may emerge from the understanding of 
the behavioral mechanisms that determine livestock selection of foraging areas (Bailey et al. 1996). Empirical evidence (Edwards et al. 1996) indicates that animals that are familiar with the food distribution should be more selective and concentrate more foraging effort at the best food locations. Computer simulations show that animals exhibiting spatial memory-based area-restricted search can obtain 1.6 times more prey items than by only using area-concentrated search, and up to 5 times more prey than by searching in a straight line (Benhamou 1994). Thus, if spatial memory is an important component of searching efficiency of cattle, modification of its role in grazing may affect grazing distribution.

The goal of this study was to quantify the role experience on search strategies and foraging efficiency of cattle. The following hypotheses were tested: (1) intake rate increases with experience as animals learn and return to locations where food was previously found; (2) long-term spatial memory allows maximum search efficiency and intake rate; (3) food search patterns of cattle can be modified by manipulating the temporal and spatial distribution of highly palatable feeds.

\section{Materials and Methods}

This experiment had 2 phases. First, steers were allowed to eat from feeders (2.8-liter plastic oil pans) until they appeared to be accustomed to search for feed in the experimental arenas. During phase 1 animals were exposed to food distributions different from those used in subsequent phases. This phase took 2 to four 20minute sessions per animal. In the second phase, each animal was allowed to forage in the experimental arena during 1 treatment session each day. This routine continued until each steer had been exposed 29 times to its treatment. These sessions were grouped into 6 periods and variables averaged within periods. Periods 1 to 6 had 4, 4, 5, 5, 5, and 6 days. Thus, period number is an indicator of level of experience. Animals, experimental arenas, treatments, measurements and analyses are described below in detail.

\section{Animals}

The 6 tamest individuals were selected from a group of 30 yearling cross-bred (Bos taurus x Bos indicus) steers. Two steers were assigned to each of 3 treatments. Average animal mass was $270 \mathrm{~kg}$. While not being tested, experimental animals grazed freely with other animals in ca. 28 ha of Old World Bluestem (Bothriochloa ischaemus (L.) Keng.). Steers were collectively fed ca. $1.1 \mathrm{~kg}$ feed/hd/day, immediately after the experimental sessions. Feed was a mixture of forages, grains, molasses, minerals, and oils in $1 / 2$-inch pellets containing more than $12.5 \%$ crude protein, $2.2 \%$ crude fat, $17 \%$ crude fiber, $0.5 \%$ calcium, $0.3 \%$ phosphorus, $0.8 \%$ salt, $1 \%$ potassium, $5,000 \mathrm{IU} / \mathrm{lb}$ vitamin $\mathrm{A}, 9$ $\mathrm{IU} / \mathrm{b}$ vitamin $\mathrm{E}$ and $10 \mathrm{~g} /$ ton chlortetracycline. Water was available ad libitum. Animal handling and care was approved by and followed guidelines of the Animal Care and Use Committee of Texas Tech University.

\section{Experimental Arenas and Treatments}

Three adjacent 50 by $50 \mathrm{~m}^{2}$ experimental arenas were fenced in an Old-World Bluestem pasture at the Texas Tech University Experimental Ranch, 15 miles south of Post, Tex. The area was almost flat and the same large-scale landmarks were visible from all arenas. The arenas simulated a 2-dimensional heterogeneous rangeland feeding environment in which a highly profitable resource (feeders with feed) was interspersed with a less profitable one (background pasture and empty feeders). Each arena had 64 locations arranged in 8 rows and 8 columns, with neighboring locations $5 \mathrm{~m}$ apart. Each location had a feeder and a stake with a visible label indicating row and column number. A handful of feed was placed around the bottom of each feeder where it was unavailable, so animals could not discriminate location of available feed by smell. Before each session, 20 of the 64 feeders were loaded with ca. $150 \mathrm{~g}$ of feed each. Loaded feeders are referred to as food locations.

Three treatments were applied by changing the spatial distribution of food locations. In treatment VR (variable-random) food locations were changed randomly for each daily trial. In treatment CR (constant-random), food locations were randomly determined once at the beginning of the experiment and remained the same thereafter. In treatment CC (constant-clumped), food locations were also constant throughout the experiment, but they were in groups of 5 consisting of a center and the 4 nearest locations surrounding the center. A variable-clumped treatment was not included because of time and labor constraints. In order to allow rapid testing of all animals within a short time I used 1 experimental arena for each treatment.

\section{Feeding Sessions}

The first 28 sessions took place between 14 July and 20 August. Session 29 took place on 4 September, after 15 days without any exposure to the treatments. Because values of measured variables in session 29 fell within the range of the other sessions of period 6, it was included in this period. Sessions started, on average, at 0841 hour (s.d. $=47 \mathrm{~min}, \mathrm{n}=29$ ) and finished at 1147 hour (s.d. $=53 \mathrm{~min}, \mathrm{n}=29$ ). Only 1 steer was observed at any given time and the same order of treatments and animals was used each day of the experiment: VR-CR-CC-VR-CR-CC. All animals were observed daily except during weekends for a total of 29 sessions each. The first 23 sessions for each animal lasted ca, 20 minutes. The duration of the last 6 sessions was reduced to 15 minutes to avoid a ceiling effect resulting from the ability of steers to find most food locations in all treatments.

\section{Variables}

All foraging sessions were observed in their entirety from a 3.5 $m$ tower. The sequence of locations visited and food locations encountered, total time eating at food locations, and total session time were measured with a hand-held stopwatch. I considered that a location was visited or encountered if the animal walked within $0.5 \mathrm{~m}$ of the feeder and lowered its head. Table 1 describes all variables and their units. Total visits was the total number of locations visited in a session, regardless of whether the location had food or whether it had been previously visited within the same session. Total visits can be greater than 64 . The total number of different locations was the number of locations visited that had not been previously visited within a session. It can vary between 0 and 64 . Number of food locations was the number of different locations encountered with food, and it can vary between 0 and 20. A map of the searching path of the animal was recorded on a scaled map of the foraging arenas. Total distance walked was calculated on the basis of the maps. Residual feed from food locations encountered was collected and weighed to 
Table 1. Measured and calculated variables.

\begin{tabular}{lccll}
\hline \hline Variable name & $\begin{array}{c}\text { Variable } \\
\text { symbol }\end{array}$ & Units & Interpretation \\
\hline Intake rate & $\mathrm{R}$ & $\mathrm{g} / \mathrm{min}$ & Intake rate during a whole session \\
\hline Intake per food location encountered & $\mathrm{i}$ & $\mathrm{g}$ & Average mass of feed consumed per location with food encountered in a session \\
\hline Residence time & $\mathrm{e}$ & $\mathrm{min}$ & Average time spent eating per location with food encountered in a session \\
\hline Search time per food location encountered & $\mathrm{s}$ & $\mathrm{min}$ & Average time spent searching per location with food encountered in a session \\
\hline Search speed & $\mathrm{S}$ & $\mathrm{m} / \mathrm{min}$ & Average walking speed while searching \\
\hline Visits per meter walked & $\mathrm{V}$ & $\mathbf{1 / m}$ & Number of locations visited per unit distance walked in a session \\
\hline Locations per visit & $\mathrm{L}$ & - & Number of different locations visited per location visited $\mathrm{n}$ a session \\
\hline Food locations per different location visited & $\mathrm{F}$ & - & Number of locations with food encountered per different location visited in a session \\
\hline Number of visits & $\mathrm{n}$ & - & Total number of locations visited in a session, including revisits \\
\hline Number of different locations visited & $\mathbf{\Phi}$ & - & Number of different locations visited in a session, excluding revisits \\
\hline Number of different locations available & $\mathrm{N}$ & - & Total number of locations in the arena; in this experiment $\mathrm{N}=64$ \\
\hline Number of locations with food available & $\mathrm{A}$ & - & $\begin{array}{c}\text { Total number of locations with food available at the beginning of a session; in this } \\
\text { experiment } \mathrm{A}=20\end{array}$ \\
\hline Number of locations without food available & $\mathrm{B}$ & - & $\begin{array}{c}\text { Total number of locations without food available at the beginning of a session; in this } \\
\text { experiment } \mathrm{B}=44\end{array}$ \\
\hline
\end{tabular}

determine quantity of food consumed. Overall intake rate $(R)$ was calculated as mass of food consumed divided by total session time. Average intake per food location (i, g/food location) was total intake divided by number of food locations encountered. Average residence time (e, min) at locations with food was time spent eating within food locations divided by total number of locations with food encountered. Time searching per food location encountered ( $\mathrm{s}, \mathrm{min} /$ food location), the reciprocal of encounter rate of food locations, was the difference between total session time and time spent eating at the food locations divided by total number of food locations encountered. Search speed (S, $\mathrm{m} / \mathrm{min}$ ) was calculated as total distance traveled divided by the difference between total session time and time spent at food locations.

For the analysis of behavioral components of intake rate and food search I partitioned intake rate and search time per food location as follows. Overall intake rate $\mathbf{R}$ was expressed as:

$$
R=\mathrm{i} /(\mathrm{s}+\mathrm{e})
$$

where:

$R=$ intake rate over the whole session ( $g / \mathrm{min})$.

$i=$ average intake per food location encountered ( $g /$ food location).

$\mathrm{s}=$ time searching per food location encountered $(\mathrm{min} /$ food location).

$\mathrm{e}=$ time spent eating per food location encountered $(\mathrm{min} /$ food location).

Time searching per food location was expressed as:

$$
\mathrm{s}=(\mathrm{S} \text { V L F })-1
$$

where:

$\mathrm{S}=$ search speed $(\mathrm{m} / \mathrm{min})$.

$\mathrm{V}=$ total visits per unit distance walked (visits $/ \mathrm{m}$ ).

$\mathrm{L}=$ ratio of different locations to visits (different locations/visit).

$F=$ ratio of food locations to different locations visited (food locations/different location), an index of food location density within the area searched.

These equations were chosen because they allow the partitioning of intake rate and search time into a series of factors that were measured directly and that quantify specific behaviors (for a similar approach to the quantification of the effects of different factors of rate of successful search see Gendron and Staddon 1983). Search speed (S) reflects the speed of locomotion while foraging. A low value of $\mathrm{V}$ indicates that the search path is directed towards a location where forage is expected, while locations along the path known to be empty are ignored. A high value of $\mathrm{V}$ indicates an expectation that food could be anywhere, so all locations along the path are visited. $\mathrm{L}$ reflects the ability to avoid locations already visited within a session; its maximum is 1.0 and indicates that each location was visited only once. Short-term spatial memory of places already visited is a mechanism by which steers could achieve a high value of $L$. Finally, F represents the ability to concentrate search on those areas where food locations are present. Long-term spatial memory is a mechanism by which steers in constant random (CR) and constant clumped (CC) could achieve high values of F. Other mechanisms are considered in detail in the discussion.

\section{Analyses}

The number of different locations visited in a session, until a certain total number of visits is completed, can be analyzed as a random variable $\Phi$ resulting from a process of sampling with replacement, because locations remain in place and can be revisited without constraints (Tillé et al. 1996). Thus, following the notation of Tillé et al. (1996), L equals $\Phi / n$, where $\Phi$ is the number of different locations visited and $n$ is the total number of visits, including revisits. Assuming that sampling is random, the expectation and variance of $\Phi / n$ were derived from equations A2 and A4 given by Tillé et al. (1996):

$$
\begin{aligned}
E[\Phi / n]= & \left(1-(N-1)^{n} / N^{n}\right)(N / n) \\
V[\Phi / n]= & n^{-2}\left((N-1)^{n} / N^{n-1}+(N-1)(N-2)^{n} / N^{n-1}-\right. \\
& \left.(N-1)^{2 n} / N^{2 n-2}\right)
\end{aligned}
$$

where:

$\mathbf{E}[\Phi / \mathbf{n}]=$ expected ratio of different locations to total visits within a session under the assumption of random search.

$\mathrm{V}[\Phi / \mathrm{n}]=$ variance of $\Phi / \mathrm{n}$

$\Phi=$ number of different locations visited in a session, excluding revisits. 
$\mathrm{n}=$ number of visits in a session, including revisits.

$N=$ population size (i.e., total number of different locations availablc; in this experiment $N=64$.

In the present experiment, the value of $L$ could vary with period or treatments because the total number of locations visited (visits) was not controlled and differed between sessions and treatments. Therefore, variance and expected value for $L$ were calculated for each session under the assumption that searching was random with replacement, and $\mathrm{L}$ was standardized as

$$
\left.\mathrm{Ls}=(\mathrm{L}-\mathrm{E}[\mathrm{L}]) / \mathrm{V}[\mathrm{L}]^{1 / 2}\right)
$$

where:

$\mathrm{Ls}=$ standardized $\mathrm{L}$ within a session (no units).

$\mathrm{L}=\Phi / \mathbf{n}$.

Standardization should remove effects of changes in mean and variance resulting from differences in total number of visits that could not be attributed with certainty to treatment effects. Analysis of $\mathrm{L}$ without standardization would have confounded differences between treatments caused by behavioral mechanisms used to avoid locations already visited, and treatment differences caused by a difference in the total number of visits. A value of Ls significantly greater than 0 indicates that steers encountered significantly more different locations per visited location than expected under the assumption of random sampling with replacement.

If one ignores the revisiting of food locations, the number of food locations (feeders with food) encountered as a proportion of the number of different locations visited $(\mathrm{F})$ can be analyzed to test whether food locations were more abundant in the area searched than expected. Because revisits are ignored, the process is analogous to random sampling without replacement. Mean and variance of $F$ were derived from equations 2 \& 3 of Tillé et al. (1996):

$$
\begin{aligned}
& \mathrm{E}[\mathrm{F}]=\mathrm{A} / \mathrm{N} \\
& \mathrm{V}[\mathrm{F}]=\mathrm{A} B(\mathrm{~N}-\Phi) /\left(\Phi \mathrm{N}^{2}(\mathrm{~N}-1)\right)
\end{aligned}
$$

where:

$E[F]=$ expected value number of food locations encountered per different location visited.

$\mathrm{V}[\mathrm{F}]=$ variance of $\mathrm{F}$.

$A=$ number of locations with food at the beginning of the session $(A=20)$.

$B=$ number of locations without feed at the beginning of the session $(B=44)$.

$\Phi=$ total number of different locations visited, excluding revisits.

$\mathrm{N}=$ total number of different locations available $(\mathrm{N}=64)$.

$\mathrm{F}$ was corrected for differences in $\mathbf{n}$ across sessions and treatments. The theoretically expected value of $F$ under the assumption of random search was a constant (20 food locations/64 locations) but its variance changed because the number of different locations visited varicd. Because the standardized value of $F$ was highly correlated with $F$ in the data set $\left(r^{2}=0.93\right)$ I analyzed and reported $F$, and not the standardized values. Values of $F$ significantly greater than expected under the assumption of random sampling without replacement would indicate the presence of a behavioral mechanism that allowed steers to perform better than random. I predicted that if smell and visual cues were eliminated as intended, $F$ would be significantly greater than expected in $\mathrm{CC}$ during period 1 , before animals had sufficient experience to remember the location of food locations. This would be explained by a pre-existing ability to detect clumps of food locations and to perform an area-restricted search, learned as a result of experience grazing in natural rangelands. As steers in constant clumps (CC) and constant random (CR) learned the locations of food, F would increase and become similar in these 2 treatments, whereas it would remain near the value expected by random search in variable random (VR).

The angles formed by the path leading to a location and the subsequent path leading away from the location were analyzed as a function of whether the locations contained food. Only responses seen in period 1 for treatments $C R$ and $C C$, and all periods for VR were used. Because steers did not know food locations, path angles at the beginning of the experiment should have reflected any pre-established rule-of-thumb. If steers were able to detect clump boundaries, sharper turns should be more frequent after exiting clumps. Because trays were on a square grid, more than $95 \%$ of the turns were $0,45,90,135$, or 180 degrees and turning angle was not a truly continuous variable. Thus, turning angles were classified into 5 categories with the following extremes: 0 , $23,68,113,158$, and 180 degrees. Frequency of each category of turns was analyzed as a function of presence of food in the current and previous locations. Locations at the corners were excluded because of the restriction on turn angles imposed.

The experiment was analyzed as a completely randomized design with repeated measures over time. The variance among animals within treatments was used as error term to test for treatment effects, whereas residual variance was used to test for period and period by treatment effects. Because the total duration of each session was changed from 20 to 15 minutes during period 6 , the analyses were separated into 2 parts: first I tested for treatment, linear period, and linear period by treatment effects for periods 1 to 5 , then, treatment effects were tested for period 6 . I compared CC vs. CR, and their average vs. VR in period 6 . These contrasts were tested using the procedure for a split-plot design described by Steel and Torrie (1980). Pre-established contrasts were used to determine if the linear period effect of $\mathrm{CC}$ differed from $\mathrm{CR}$, and if the average linear trend for $\mathrm{CC}$ and $\mathrm{CR}$ differed from VR.

The importance of the different components of intake rate and encounter rate were studied by path analysis ( $\mathrm{Li} 1975$ ) and reported using the method described by Williams et al. (1990). Path analysis partitions the coefficient of multiple correlation into direct effects (standardized partial regression coefficients) of each explanatory variable on the dependent variable, and indirect effects of each independent variable through its conelation with other independent variables. The structure of associations among components of intake rate was studied by performing a MANOVA and analyzing the variance-covariance matrices (SAS Institute 1994).

\section{Results}

First I describe how intake rate, food location residence time and search time per food location responded to experience and food distribution treatments. The importance of each component of intake rate is assessed by path analysis. Second, I describe the effects of experience and food distribution on the components of search time per food location. Effects of experience and food distribution on intake rate and search time per food location are traced to their behavioral components. 

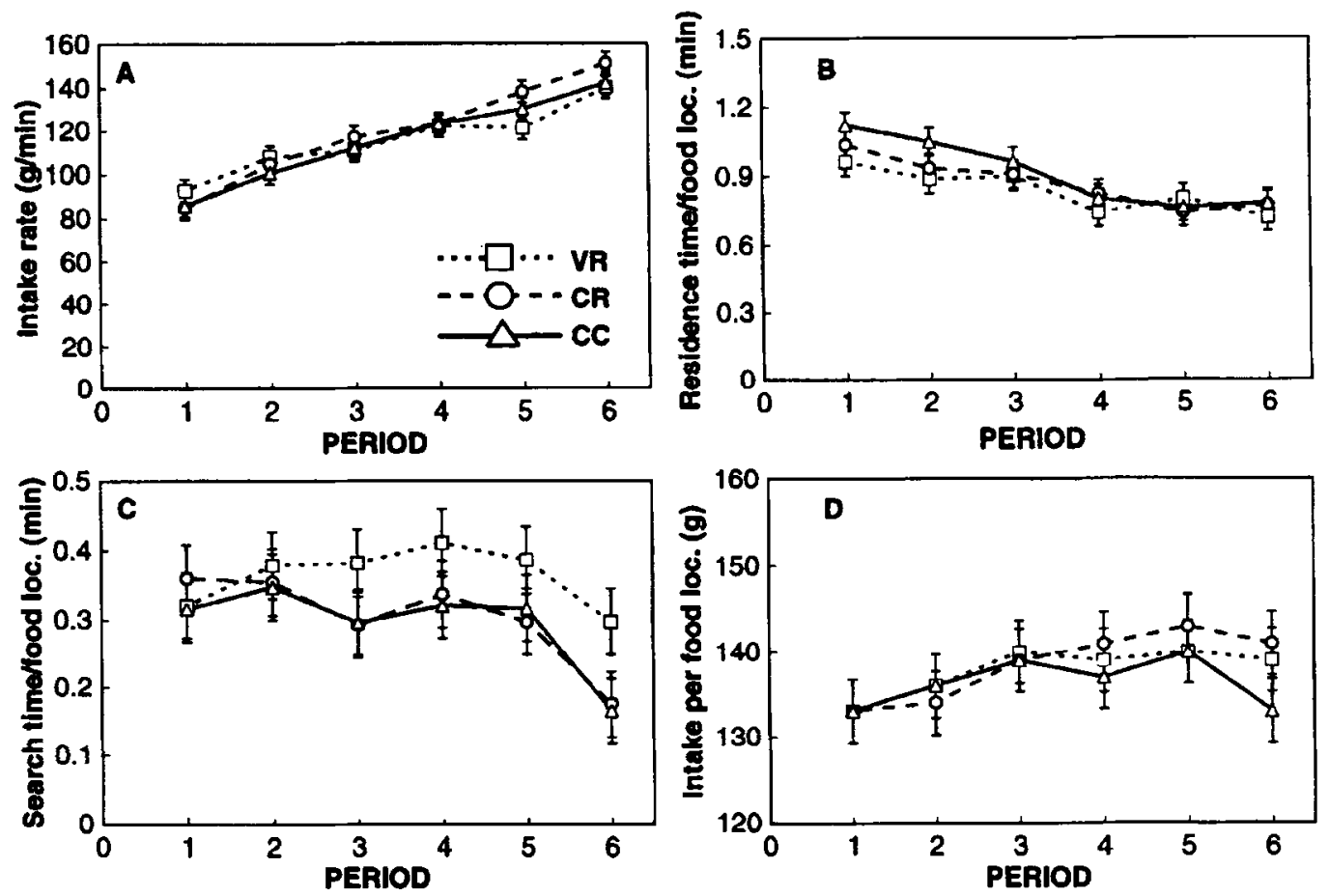

Fig. 1. Effects of experience (increasing over periods) and food distribution on intake rate (A), food location residence time (B), search time per food location (C), and intake per food location by steers (D).

\section{Intake Rate and Its Components}

Intake rate $(\mathrm{R})$ within sessions increased with increasing experience (Fig. 1A and Table 2) in all treatments. The linear period $X$ treatment interaction $(P=0.06)$ was further explored by predetermined contrasts. The linear increase in treatments constant random (CR) and constant clumped (CC) was similar (P >0.10), and their average was significantly greater than in variable-random (VR) $(P=0.02)$, where location of food was changed daily. Residence time per encountered food location (e) was not affected by food distribution and declined significantly with increasing experience (Table 2, Fig. 1B).

Average search time per food location within sessions (s) did not respond to experience or food distribution in the first 5 periods $(\mathrm{P}>0.50$, Fig. 1C). In period $6, \mathrm{~s}$ in the treatments with constant food locations (CC \& CR) was $57 \%$ of that in VR (P = 0.03). Intake per food location (i, Fig. ID) exhibited a significant linear increase over the first 5 periods $(P=0.000)$, in spite of the decline in residence time.

Path analysis (Fig. 2 and Table 3) showed that residence time was the variable that had the most important direct effect on intake rate, followed by search time per food location (s) and intake per food location (i). Residence time had the greatest correlation with intake rate, mostly by its significant direct effect ( $P$ $<0.0000$ ). As residence time declined, intake rate increased.

\section{Search Characteristics and Movement Patterns}

Various patterns of response were found in the components of search time per food location. Search speed (S), the average speed at which the path between food locations was traveled, declined significantly with experience, mainly from period 1 to 2 (Fig. 3A and Table 2). No differences in $S$ were detected among treatments.

The number of location visits per $m$ of path (V) exhibited a significant treatment by period interaction $(P=0.002$, Fig. 3B and
Table 2). V declined linearly in constant-random (CR) and constant clumped (CC), whereas it remained high in variable-random (VR). As steers in the treatments with constant food location locations developed mechanisms to concentrate their search in the areas where food was previously found, they progressively ignored other locations as they walked to known food locations. Steers in VR always visited most locations in their path.

The standardized value $L_{s}$ (Fig. 3C) is corrected for changes in expectation and variance of $L$, and therefore, departure from a value of 0 reflects a nonrandom search pattern. Where food locations were constant and clumped (CC), $\mathrm{L}_{\mathbf{s}}$ did not differ from zero, regardless of the level of experience, indicating a pattern of

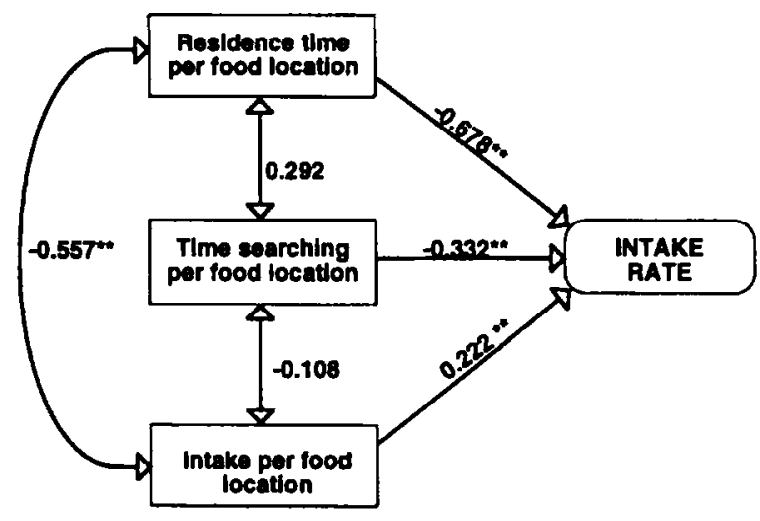

Fig. 2. Path analysis of intake rate as a function of its components. The total correlation between intake rate and each component is partitioned into direct and indirect effects. Double-headed arrows indicate correlations; single-headed arrows indicate direct effects. Indirect effects are the product of a correlation and a direct effect. One and 2 asterisks indicate significance at 5 and $1 \%$, respectively. 
Table 2. Probability values for error type $I(\alpha)$ for effects shown in Figures 1 and 3 . R, intake rate; e, food location residence time; $s$ search time per food location; $i$, intake per food location; $S$, search speed; V, food locations visited per meter walked; $\mathbf{L}_{\mathbf{s}}$, standardized number of different locations per visit; F, food locations encountered per different location visited; $d$, distance walked per unit intake.

\begin{tabular}{|c|c|c|c|c|c|}
\hline \multirow[b]{2}{*}{ Variable } & \multicolumn{3}{|c|}{ Periods 1-5 } & \multicolumn{2}{|c|}{ Period 6} \\
\hline & Treat. & $\begin{array}{l}\text { Period } \\
\text { (Linear) }\end{array}$ & $\begin{array}{l}\text { Treat. } \\
\text { x Per. }\end{array}$ & $\begin{array}{c}\text { CR vs. } \\
\text { CC }\end{array}$ & $\begin{array}{c}\text { CR \& CC } \\
\text { vs. VR }\end{array}$ \\
\hline $\begin{array}{c}\mathbf{R} \\
\text { intake rate }\end{array}$ & 0.929 & 0.000 & 0.057 & 0.634 & 0.677 \\
\hline $\begin{array}{l}\text { e } \\
\text { residence time }\end{array}$ & 0.770 & 0.000 & 0.055 & 0.939 & 0.635 \\
\hline $\begin{array}{l}\text { s } \\
\text { search time }\end{array}$ & 0.813 & 0.975 & 0.147 & 0.857 & 0.034 \\
\hline $\begin{array}{c}\text { i } \\
\text { intake per } \\
\text { location with } \\
\text { food }\end{array}$ & 0.914 & 0.000 & 0.357 & 0.190 & 0.712 \\
\hline $\begin{array}{c}\text { S } \\
\text { search speed }\end{array}$ & 0.911 & 0.002 & 0.940 & 0.465 & 0.315 \\
\hline $\begin{array}{c}V \\
\text { locations visited } \\
\text { per } m \text { walked }\end{array}$ & 0.221 & 0.000 & 0.002 & 0.864 & 0.002 \\
\hline $\begin{array}{l}\text { Ls } \\
\text { standardized } \\
\text { number of } \\
\text { different } \\
\text { locations visited } \\
\text { per location } \\
\text { visited }\end{array}$ & 0.156 & 0.852 & 0.003 & 0.073 & 0.002 \\
\hline $\begin{array}{c}F \\
\text { number of food } \\
\text { locations per } \\
\text { different } \\
\text { location }\end{array}$ & 0.132 & 0.000 & 0.000 & 0.446 & 0.000 \\
\hline $\begin{array}{l}\text { d } \\
\text { distance walked } \\
\text { per unit intake }\end{array}$ & 0.576 & 0.000 & 0.001 & 0.444 & 0.001 \\
\hline
\end{tabular}

search by which locations were revisited at random. The clumping of patches in CC may have motivated animals to return to locations around areas where food was previously found, thus increasing the chances to revisit locations. This interpretation implies that steers were able to detect clumps of food locations, which was not corroborated by the analyses of search paths and angles. Steers in $C R$ and VR exhibited values of $L_{s}$ significantly greater than $0(P<0.01)$ reflecting an avoidance of locations already visited. While initial values of $L_{S}$ were similar for $V R$ and CR during period 1, Ls declined in CR and increased in VR with increasing experience, yielding a significant interaction $(P=0.03)$. This pattern of response is consistent with the similarity of treatments VR and CR before animals had learned food locations. When location of food is uncertain, steers seem to exhibit a pattern of search that prevents revisits. This may involve short-term spatial memory or, more simply, a tendency to walk in a straight line.

The proportion of different locations visited that contained food (F) exhibited a clear treatment by period (experience) interaction $(\mathrm{P}<0.0001$, Fig. 3D and Table 2). Treatments CR and CC exhibited a linear increase of $F$ over periods whereas VR remained constant at $0.36( \pm 0.009)$, a value greater than the expected 0.31 $(P<0.01)$. In period 1 , when food locations were still unknown, steers in $\mathrm{CC}$ found more $(\mathrm{P}=0.06)$ food locations within the area searched than those in VR and CR. This tendency is interpreted as evidence of a subtle mechanism to exploit the clumped distribution of food locations not detected by the analysis of movement
Table 3. Path analysis of intake rate $(R)$ as a function of food location residence time (e), intake per food location (i), and time searching per food location (s). Values on the main diagonal are standardized partial regression coefficients that indicate direct effects. The other values indicate the indirect effects of the row variable via the column variable and each is the product of the correlation between 2 explanatory variables and a direct path coefificient.

\begin{tabular}{|c|c|c|c|c|c|}
\hline & i & $\mathbf{s}$ & e & Total r & $\mathbf{R}^{2}$ \\
\hline $\mathbf{i}$ & 0.222 & 0.036 & 0.378 & 0.636 & 0.934 \\
\hline $\mathbf{s}$ & -0.024 & -0.332 & -0.198 & -0.554 & \\
\hline $\mathbf{e}$ & -0.124 & -0.097 & -0.678 & -0.898 & \\
\hline
\end{tabular}

characteristics, but also reflected in the low values of $\mathrm{L}_{\mathrm{s}}$ in $\mathrm{CC}$ during period 1 .

Although intake rate did not differ among treatments $(\mathbf{P}=$ 0.93 ), the response of distance walked per unit of intake mirrored that of $F$ (Fig. 3E). As a result of experience, steers in constant clumped (CC) and constant-random (CR) became more efficient at finding food than in variable-random (VR).

Searching time per food location, $s$, was strongly determined by negative direct effects of number food locations enountered per different location visited, $F$, and search speed, $S$ (Table 4 and Fig. 4). Overall, $F$ was the most important determinant of $s$ because of its large direct effect and significant correlations with the rest of the components. Because $S$ was negatively correlated with $F(r=$ $-0.345, P<0.05$ ), it had a positive indirect effect on $\mathrm{s}$ via $\mathrm{F}$, and its total effect was weak. More than $80 \%$ of the negative covariance between $\mathrm{F}$ and $\mathrm{S}$ was a result of treatment effects, because steers in the treatment where food location locations were changed daily (VR) tended to search faster and were less efficient at finding food than those in the other 2 treatments. The other components, $\mathrm{V}$, and $\mathrm{Ls}$ had minor negative direct effects on $\mathrm{s}$.

\section{Movement Patterns}

No relationship was found between the success in finding food and the turning angle to the next location $(P>0.13)$. The pattern of turns and the tortuosity of the search path were not related to the sequence of failures and successes in the previous 2 or 3 locations $(P>0.10)$. When food locations were unknown, steers exhibited a strong tendency to continue moving in the same direction, regardless of the sequence of failures and successes.

Table 4. Path analysis of search time per food location (s) as a function of search speed (S), number of locations visited per meter walked (V), standardized number of different locations per visit $\left(L_{\mathrm{S}}\right.$ an index of avoidance of recently visited locations), and ratio of food locations to different locations visited ( $F$, an index of the ability to concentrate search effort in areas where food was located). Values on the main diagonal indicate direct effects. The other values indicate the indirect effects of the row variable via the column variable. Statistical meaning of numbers is as in Table 3. Coefícients allow comparison of dinect effects among variables and of direct and indirect effects within variables.

\begin{tabular}{lcccccc}
\hline & $\mathbf{S}$ & $\mathbf{V}$ & \multicolumn{1}{c}{$\mathbf{L}_{\mathbf{s}}$} & \multicolumn{1}{c}{$\mathbf{F}$} & \multicolumn{1}{c}{ Total $\mathbf{r}$} & $\mathbf{R}^{\mathbf{2}}$ \\
\hline $\mathbf{S}$ & $\mathbf{- 0 . 6 4 8}$ & 0.063 & $\mathbf{0 . 0 6 9}$ & 0.442 & -0.340 & 0.894 \\
$\mathbf{V}$ & -0.144 & $\mathbf{- 0 . 2 8 5}$ & -0.069 & -1.044 & 0.545 & \\
$\mathbf{L}_{\mathbf{s}}$ & -0.223 & -0.098 & $-\mathbf{0 . 2 0 2}$ & 0.821 & 0.298 & \\
$\mathbf{F}$ & 0.224 & $\mathbf{0 . 2 3 2}$ & 0.129 & -1.280 & -0.695 & \\
\hline
\end{tabular}



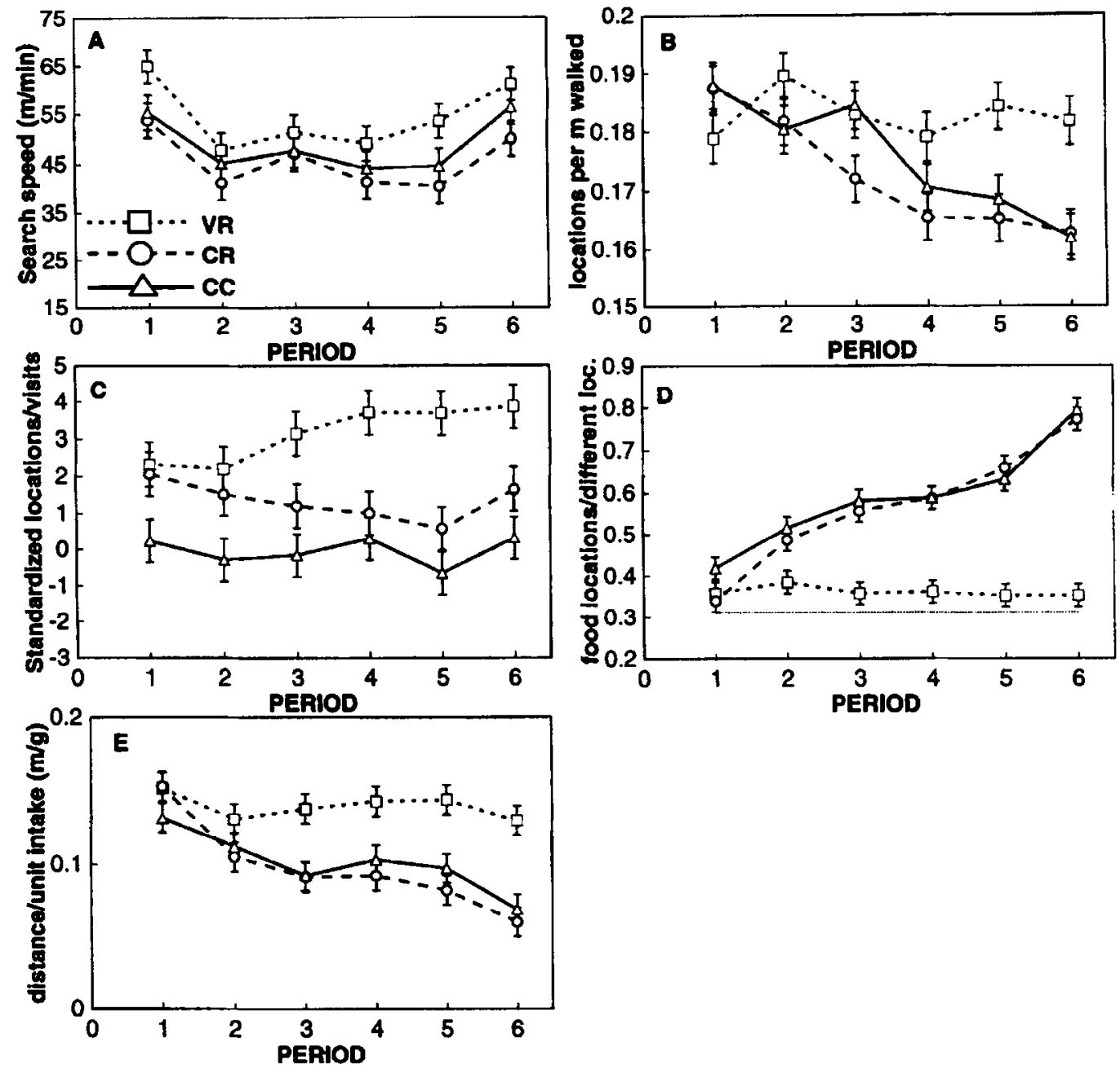

Fig. 3. Effects of experience and food spatial distribution on the components of search time per food location and the distance walked per unit intake, an index of foraging efficiency. The horizontal dotted line in graph $D$ indicates the value expected from random sampling without replacement.

\section{Discussion}

As a result of experience with the task, steers foraging in areas with constant food locations increased their ability to find food, decreased the distance walked per unit of intake, and increased intake rate. Steers foraging in areas with randomly varying food locations achieved intake rates not different from constant clumped (CC) and constant-random (CR) by walking faster and by establishing a systematic search pattern that resulted in more locations visited per $m$ walked and fewer revisits. On average, steers in CC, $\mathrm{CR}$ and variable random (VR) found $16.7( \pm 1.5)$, $16.3( \pm 1.5)$, and $15.3( \pm 1.5)$ food locations per session during the last period of the experiment.

If one views foraging by a large herbivore as the search for and partial depletion of acceptable food locations (Astrom et al. 1990; Danell et al. 1991; Laca et al. 1994), there are 2 behavioral mechanisms by which intake rate and efficiency of foraging can increase. The forager can increase the rate at which food locations are depleted once encountered and/or increase encounter rate of food locations. Encounter rate of food locations can be enhanced by concentration of search effort in areas where food locations are more abundant, avoidance of areas already depleted, and faster search speed. Steers were able to implement all mechanisms as they gained experience. There was strong evidence that when food locations were constant, long-term spatial memory was the most important factor determining encounter rate of food locations.

\section{Residence Time and Intake per Food Location}

Steers experienced a negative feedback between residence time and intake rate $(R)$. Actual residence time did not differ among treatments, but declined significantly as a function of experience with the foraging task. I surmise that steers responded to this feedback, steadily reducing residence time and increasing intake rate as they became more familiar with the task. The fact that intake per food location actually increased with experience, in spite of the reduction in residence time, indicates that steers learned to consume the feed faster while at a food location.

\section{Role of Spatial Memory}

The ratio of number of food locations to number of different locations visited (F) was the most important factor determining 


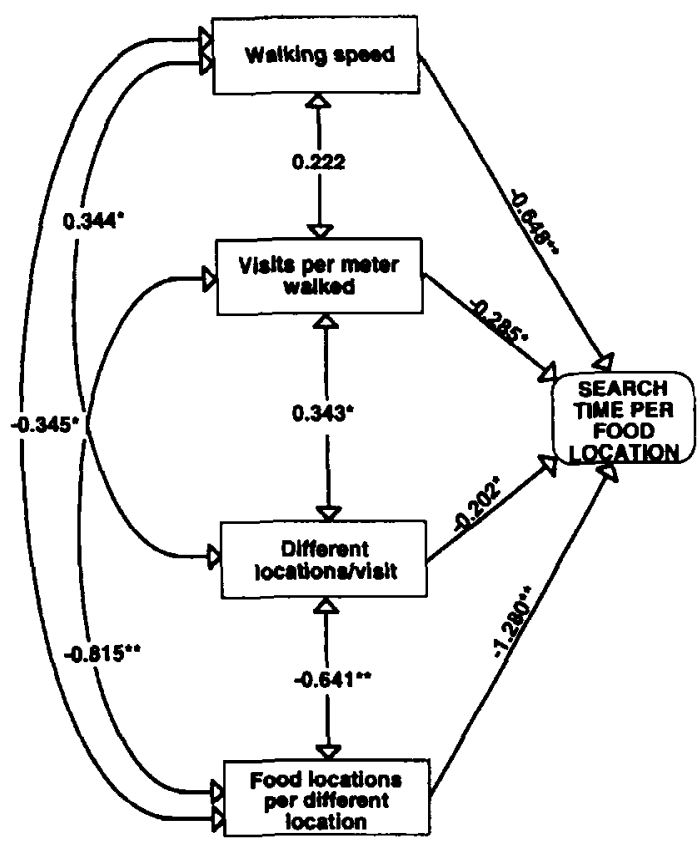

Fig. 4. Path analysis of search time per food location as a function of its components. Symbols are as in Figure 2.

encounter rate of food locations. Even when food locations were randomized daily $(V R), F$ was $16 \%$ greater $(P<0.01)$ than expected by random search. In the other 2 treatments, the ratio increased to more than 2.5 times the expected random search value. How did steers manage to find the food? I argue that spatial memory was a key mechanism.

A value of $F$ greater than expected may result from a series of mechanisms: observation of food placement while at the holding pen, perception of smell or other cues directly linked to the food, perception of trails or markings left during previous visits, rulesof-thumb or general algorithms, and long-term spatial memory (Olton 1978). With the exception of the first 2 mechanisms proposed, all mechanisms require that food locations be constant or have a certain spatial pattern on which an algorithm could work. None of these conditions were met in variable random (VR), so, in this treatment the slightly high value of $F$ is attributed to perception of cues directly linked with the food such as odor, ability of steers to see whether trays contained feed from a distance greater than $0.5 \mathrm{~m}$, or learning of locations by observing where feed was placed. Although I attempted to control for odor cues by placing a little unavailable food in all locations, the quantity of unavailable food was less than that in food locations, it was not equally exposed to wind, and it was not replenished daily. Therefore, it is possible that food locations had a more intense smell than empty locations. Yet, steers often walked near food locations but did not discover them, and very frequently put their noses into empty trays before realizing that they were empty. This suggests that the effects of smell and sight on detection of feed from distances greater than $0.5 \mathrm{~m}$ was limited. On the basis of the behavior of steers while at the holding pen and the distance and topography between holding pen and arenas I believe it is very unlikely that steers found feed by observing where we placed it. Because VR offered equal conditions of odor and visual cues, it was a control for constant random (CR) and constant clumped (CC). The effects in $\mathrm{CR}$ and $\mathrm{CC}$ beyond the value of $\mathrm{F}$ measured in VR must be attributed to mechanisms other than direct perception of cues associated with the food or ability to observe where food was placed.

The results provide evidence that the increase in $\mathrm{F}$ observed in $\mathrm{CR}$ and $\mathrm{CC}$ resulted from spatial memory. This evidence is based on the elimination of the alternative mechanisms. The use of markings was very unlikely because it would have required the ability to facultatively mark food locations with lasting odor or visual cues. The experiment took 51 days over which significant rain storms and periods of high temperatures alternated, and the vegetation changed significantly in quantity and phenological stage. The use of trails was very unlikely because steers would not be able to distinguish a trail that led to an empty location from one that led to a food location. No trails between food locations were visible in the experimental areas, and the pattern of transitions from one food location to the next evinced multiple pathways, not a fixed one.

General algorithms for movement, such as increasing the frequency of turns upon finding food, did not seem to explain the high food-finding efficiency, either. The use of general algorithms would have been possible only in $\mathrm{CC}$, where food locations were clumped. In a clumped distribution the presence of food in a location changes the expectation of presence of food in neighboring locations, so a search algorithm that increases search effort around food locations leads to greater search efficiency. Nevertheless, except for period $1, F$ was essentially the same in $\mathrm{CR}$ and $\mathrm{CC}$. The greater success of steers in $\mathrm{CC}$ during period 1 may have been related to the clumping of food locations. Yet, turning angles were not related to the presence of food in recently visited locations as it would be expected if steers were able to recognize clump boundaries. Although an algorithm may have been used in the early periods, its effects were masked by the effects of spatial memory.

This experiment strongly suggests that spatial memory is an important mechanism that determines foraging efficiency of cattle. It is likely that the importance of this and other mechanisms varies with the spatial scales at which the different foraging decisions operate (Bailey et al. 1996; Laca and Ortega 1996). Spatial memory requires the storage of a certain quantity of information per site or location. As the number of sites increases the accuracy of the memory declines (Olton et al. 1981). Thus, it is reasonable to hypothesize that grazers use the limited memory capacity for the most profitable and persistent resources, such as water, cover, or large areas with good forage. Long-term, reference spatial memory would not be relevant at small scale (bites, feeding stations, food locations) because of the large number and frequency of decisions involved (Senft et al. 1987). Although cattle have the ability to develop short-term memory of patches visited within a feeding bout or feeding sites visited in previous grazing bouts (Bailey et al. 1989a) this may not be a very important mechanism in the avoidance of depleted food locations in rangelands because simple rules of thumb can accomplish the same results by systematic search patterns. Thus, I hypothesize that foraging efficiency and spatial grazing patterns at the landscape scale are more directly linked to long-term spatial memory of cattle.

\section{Working and Reference Memory}

The present experiment differed from most of the classic (e.g. Olton 1978; Olton et al. 1981; Olton and Samuelson 1976) and more recent works on spatial memory of livestock (e.g., Bailey et 
al. 1989a; Bailey et al. 1989b) in that I focused on long-term or reference memory. Additionally, I partitioned the effects on intake rate into factors determined by short-term or working memory, such as avoidance of locations already visited, and factors determined by reference memory, such as the ratio of food locations to total different locations visited.

Olton et al. (1981) described 2 opposing strategies in relation to spatial choice, "win-shift" and "win-stay," to indicate that predators have to opt between avoiding or returning to places where food was previously found. Cattle exhibit spatial strategies that are significantly more complex than the behaviors potentially explained by the win-shift/stay dimension. In the present experiment steers exhibited the ability to use both strategies at different time scales. In the short term (within sessions), foraging efficiency was improved by using working memory to avoid locations already visited. This was reflected by $L_{s}$ values greater than 1 in variable random (VR) and constant random (CR). In the long term (between sessions), foraging efficiency was improved in treatments with constant food locations by returning to locations where food was found in previous sessions. This was reflected by values of $F$ greater than expected by random search and which increased with experience. In principle, both strategies can be used simultaneously. However, the emphasis on one or the other strategy appeared to depend on the variability of food locations. When food locations were constant over time and clumped in space (CC), steers emphasized a long-term win-stay strategy based on spatial memory by returning to food locations found in previous sessions (Fig. 3), and performed an area-restricted search that resulted in a short-term performance (avoidance of locations visited within a session) not different from random (neither win-shift nor win-stay). Conversely, when food locations were variable over time steers emphasized a short-term win-shift strategy and became progressively better at avoiding locations already visited within a session.

\section{Conclusions and Practical Implications}

The present results support the hypothesis that intake rate increases as cattle learn and return to locations where food was previously found. However, steers also used other behavioral mechanisms such as a systematic search pattern, that allowed similar increases of intake rate in the absence of spatial memory. As hypothesized, spatial memory allowed the highest foraging efficiency, measured as intake per unit distance walked. Contrasting search strategies resulted from exposing steers to different temporal and spatial distributions of a high quality feed. This supports the hypothesis that search pattern can be manipulated through management.

Steers in the treatments with constant food locations were more efficient and established much shorter and directed search paths, interacting with a small proportion of the pasture area. Conversely, animals that were unable to use spatial memory were less efficient and established a systematic search pattern, interacting with most of the available area. Therefore, a more uniform grazing pattern may be promoted by impeding spatial memory and preventing animals from developing high expectations of concentrated food rewards in specific locations. This might be accomplished by frequent movements among grazing units or by training livestock to expect high rewards (e.g., supplements) in unpredictable locations. Such a management scheme would not be equivalent to current rotational grazing and supplementation schemes because all grazing units could be stocked at any given time, and no single set of locations would be used for supplemental feeding. Finally, inhibition of spatial memory might result in lower animal performance, due to the lower foraging efficiency. From a production point of view, the magnitude of this effect could counterbalance the potential improvements in grazing distribution and should certainly be investigated. If negative effects on productivity are not major, any tool that improves grazing distribution should make livestock production more compatible with conservation of rangeland resources.

\section{Literature Cited}

Atrom, M., P. Lundberg, and K. Danell. 1990. Partial prey consumption by browsers: trees as patches. J. of Anim. Ecol. 59:287-300.

Bailey, D. W. 1988. Characteristics of spatial memory and foraging behavior in cattle. Ph.D. Diss., Colorado State Univ.

Bailey, D. W., J. E. Gross, E. A. Laca, L. R. Rittenhouse, M. B. Coughenour, D. M. Swift, and P. L. Sims. 1996. Mechanisms that result in large herbivore grazing distribution patterns. J. of Range Manage. 49:386-400.

Bailey, D. W., L. R. Rittenhouse, R. H. Hart, and R. W. Richards. 1989a. Characteristics of spatial memory in cattle. Appl. Anim. Behav. Sci. 23:331-340.

Bailey, D. W., L. R. Rittenhouse, R. H. Hart, D. M. Swift, and R. W. Richards. 1989b. Association of relative food availabilities and locations by cattle. J. of Range Manage. 42:480-482.

Benhamou, S. 1994. Spatial memory and searching efficiency. Anim. Behav. 47:1423-1433.

Danell, K., L. Edenius, and P. Lundberg. 1991. Herbivory and tree stand composition: moose patch use in winter. Ecol. 72:1350-57.

Edwards, G. R., J. A. Newman, A. J. Parsons, and J. R. Krebs. 1996. The use of spatial memory by grazing animals to locate food patches in spatially hetcrogencous environments-an example with sheep. Appl. Anim. Behav. Sci. 50:147-160.

Gendron, R. P. and J. E. R. Staddon. 1983. Searching for cryptic prey: the effect of search rate. Amer. Nat. 121:172-186.

Holechek, J. L., R. D. Pieper, and C. H. Herbel. 1995. Range management. Principles and practices. Prentice Hall, Englewood Cliffs, N. J.

Laca, E. A., R. A. Distel, T. C. Griggs, and M. W. Demment. 1994. Effects of canopy structure on patch depression by grazers. Ecol. 75:706-716.

Laca, E. A. and I. M. Ortega. 1996. Integrating foraging mechanisms across spatial and temporal scales, p. 129-132. In: N. E. West, (ed.), Fifth International Rangeland Congress. Vol. 2, Soc. for Range Manage, Salt Lake City, Utah.

Li, C. C. 1975. Path analysis-a primer. The Boxwood Press, Pacific Grove, Calif.

Olton, D. S. 1978. Characteristics of spatial memory, p. 341-373. In: S. H. Hulse, H. Fowler and W. K. Honig, (eds.), Cognitive processes in animal behavior. Lawrence Erlbaum Assoc., Hillsdale, N. J.

Olton, D. S., G. E. Handelmann, and J. A. Walker. 1981. Spatial memory and food searching strategies, p. . In: A. C. Kamil and T. D. Sargent, (eds.), Foraging behavior. Ecological, ethological, and psychological approaches. Garland STPM Press, New York.

Olton, D. S. and R. J. Samuelson. 1976. Remembrance of places passed: spatial memory in rats. J. of Exp. Psych: Anim. Behav. Proc. 2:97-116.

SAS Institute, Inc. 1994. JMP Statistics and graphics guide. SAS Institute. Cary, N.C.

Senft, R. L., M. B. Coughenour, D. W. Bailey, L. R. Rittenhouse, O. E. Sala, and D. M. Swift. 1987. Large herbivore foraging and ecolngical hierarchies: landscape ecology can enhance traditional foraging theory. BioSci. 37:789-799.

Steel, R. G. D. and J. H. Torrie. 1980. Principles and procedures of statistics. McGraw Hill, New York.

Tillé, Y., J. A. Newman, and S. D. Healy. 1996. New tests for departures from random behavior in spatial memory experiments. Anim. Learn. and Behav. 24:327-340.

Williams, W. A., M. B. Jones, and M. W. Demment. 1990. A concise table for path analysis statistics. Agron. J. 82:1022-1024. 